\title{
Annotations
}

\section{In utero transfer to specialist centres}

As soon as neonatal intensive care had been shown to reduce mortality in sick infants, the development of neonatal transport teams and of procedures for admitting such babies was a logical step forward. There is evidence that infants who are transferred to specialist centres for treatment of respiratory failure and allied problems do well, but despite the enthusiasm at some centres there is comparatively little evidence to support the transfer of the mother and her fetus to a special unit before delivery.

In areas of the world where transport is poor and primary obstetric care limited, mothers have been transferred to hospital centres for some time. In west Africa the use of 'maternity villages' has had some success. Women at risk have been identified by village midwives and transferred a few weeks before delivery, thus saving a long walk in obstructed labour. ${ }^{1}$ A similar system operated some years ago in rural Iowa, USA, but is now obsolete because of improved transport. ${ }^{2}$ These transfer systems were largely organised for the mother's well being rather than that of the fetus.

States such as Arizona, USA, have successfully organised a combined antenatal and postnatal transfer system, with marked improvement in neonatal survival..$^{3-4}$ With a population density of 6 persons per square mile outside the two main cities and vast distances to travel, the advisability of antenatal transport for maternal or fetus well being was not questioned. Nevertheless, the figures of Giles et al. suggest that although the mortality rate among infants transferred to a special centre before birth was lower than that among those transferred after birth, the differences were not important when mortality rates for birthweight and gestational age were compared.

In the UK several centres reporting their results with in utero transfer, point to lower mortality for birthweight or gestational age, but in none are these differences statistically significant. ${ }^{5-7}$ It is notable, however, that their infant mortality rates are considerably lower than the national average in both the antenatally and postnatally transferred groups. In one series of infants from California the mortality rate was slightly higher in antenatally transferred infants, although not significantly so. ${ }^{8}$ Variables apart from gestational age and birthweight are important in determining neonatal survival, and risk factors identified before birth may not be as serious as those identified during or after delivery. Without a controlled trial (which is unlikely now to be done) these factors cannot accurately be allowed for.

It is not surprising then that antenatal transfer has come in for considerable criticism, and not always from peripheral hospitals. The inability to assess accurately the likelihood of the fetus to require intensive care after delivery means that between $50 \%$ and $90 \%$ of transferred fetuses did not need to travel..$^{710}$ Many feel that such a degree of accuracy is reasonable, but lack of provision at regional centres in the UK may mean that the facilities available are filled with relatively well infants, to the exclusion of others less fortunate. ${ }^{10}$ Most transferred fetuses not requiring intensive care were of more than 33 weeks' gestation, and had been identified by ultrasound as being growth retarded or were growth retarded and consequently thought to be less than 33 weeks' gestation. ${ }^{7}$ The accurate estimation of gestational age using early ultrasound examination and determining antenatal referral largely by gestational age could improve the selection of those fetuses only which might well require intensive care.

Concern about the psychological and physical problems of transferring mothers has been expressed. ${ }^{6}$ Although most centres have experienced few problems, such as delivery during transport, little consideration has been given to the anxiety and relative isolation of the mother at this sensitive time.

The difference in obstetric management between the district hospital and the specialist centre is not likely to be greater than that among individual obstetricians, except that the presence of a neonatal intensive care unit allows the obstetrician to take the risk of delivering the fetus earlier; usually by caesarean section. Ideally all fetuses would be delivered at the optimal time and this may be seen as one argument for antenatal transfer. In Ohio infants of $<1250 \mathrm{~g}$ weight had a $40 \%$ better chance of survival if delivered at a regional centre, than at a district hospital. When the mortality rate for birthweight was considered, however, survival was improved only in infants of less than 1000 g. ${ }^{11}$ 
If mortality is reduced slightly, or not at all, by antenatal transfer perhaps such a scheme may be supported on the grounds of improved quality of survival. It can be, but since it has proved difficult enough to convince the profession that even neonatal care improves neurodevelopmental outcome enthusiasm for antenatal transfer is unlikely. The principal causes of poor outcome in preterm infants are ischaemic and haemorrhagic lesions of the brain, secondary to inadequately controlled respiratory failure. Several authors have commented on the lower rates of intraventricular haemorrhage in inborn and antenatally transferred infants compared with postnatally transferred infants. ${ }^{12}$ Population differences, however, preclude fair comparison between these groups. Clark and co-workers found intraventricular haemorrhage to be four times more common in outborn than inborn infants. No significant differences in obstetric or infant risk factors were seen between the two groups, although the numbers were small. Important differences were seen, however, in therapeutic risk factors, such as the use of prenatal steroids and methods of resuscitation of the infant. ${ }^{13}$ Prevention of intraventricular haemorrhage in low birthweight infants has been claimed, frequently using caesarean section and immediate and vigorous respiratory support. ${ }^{14}$ Although the ability to prevent intraventricular haemorrhage by these methods has yet to be confirmed by other centres, early and adequate respiratory support to the very low birthweight infant is vital to reduce severity, and the duration of later respiratory disease, and probably therefore to improve neurodevelopmental outcome. If antenatal transfer does anything it enables such infants to receive proper care from birth, rather than deteriorate initially. But antenatal transfer can be seen as a temporary measure only, since although it is impracticable for every maternity hospital to staff an intensive care unit, the provision of thorough resuscitation and short-term respiratory support for low birthweight infants before transfer should be mandatory wherever infants are delivered. Lack of staff training, and to a lesser extent lack of equipment, means that this simple requirement is not always met today, and that antenatal transfer seems the better alternative.

The development of perinatal care in the UK has been uneven and arbitrary, larger centres having laid claim to the title of regional centre rather than the health regions developing a service designed for their own needs. In the future we must correct this, mainly by better provision and education of staff, so that district hospitals are free to decide upon the optimal management of mothers at risk and their babies. Better training together with better communication will lead to the referral centre continuing treatment begun at the district hospital rather than coming to the rescue, at whatever stage that might be.

\section{References}

1 Minkler D. Commentary to Giles H R, Isaman J, Moore W J, Christian C D. Am J Obstet Gynecol 1977; 128: 406.

2 Christian D. Commentary to Giles H R, Isaman J, Moore W J, Christian C D. Am J Obstet Gynecol 1977; 128: 407.

${ }^{3}$ Harris $\mathbf{T} \mathbf{R}$, Isaman $\mathbf{J}$, Giles $\mathbf{H} \mathbf{R}$. Improved neonatal survival through maternal transport. Obstet Gynecol 1978; 52: 294-300.

4 Giles H R, Isaman J, Moore W J, Christian C D. The Arizona high-risk maternal transport system-an initia view. Am J Obstet Gynecol 1977; 128: 400-7.

5 Blake A M, Pollitzer M J, Reynolds E O R. Referral of mothers and infants for intensive care. $\mathrm{Br}$ Med J 1979; ii: 414-6.

6 Crowley P, Lamont R, Elder M G. The obstetric care of the fetus transferred in utero. J Obstet Gynecol 1982; 2: 129-33.

7 Lobb M O, Morgan M E I, Bond A P, Cooke R W I. In utero transfers on Merseyside. Br J Obstet Gynaecol 1983 ; in press.

8 Modanlou H D, Dorchester W, Freeman R K, Rommal C. Perinatal transport to a regional perinatal center in a metropolitan area: maternal versus neonatal transport. Am J Obstet Gynecol 1980; 138 : 1157-64.

9 Goodlin R C. Commentary to Giles H R, Isaman J, Moore W J, Christian C D. Am J Obstet Gynecology 1977; 128: 406.

10 Chiswick M L. Perinatal referral: a time for decisions. Br Med J 1982; 285 : 83-4.

11 Cordero L, Backes C R, Zuspan F P. Very low birth weight infant-influence of place of birth on survival. Am J Obstet Gynecol 1982; 143: 533-7.

12 Levine M I, Fawer C L, Lamont R F. Risk factors in the development of intraventricular haemorrhage in the preterm neonate. Arch Dis Child 1982; 57: 410-7.

13 Clark C E, Clyman R I, Roth R S, Sniderman S H, Lane $B$, Ballard $\mathbf{R}$ A. Risk factor analysis of intraventricular hemorrhage in low birth weight infants. J Pediatr 1981; 99: 625-8.

14 Lou H C, Phibbs R H, Wilson S L, Gregory G A. Letter: Hyperventilation at birth may prevent early periventricular haemorrhage. Lancet 1982; i: 1407.

R W I COOKE

Liverpool Maternity Hospital, Oxford Street, Liverpool L7 7BN 